\title{
AMBIENTES DE SUPORTE PARA EDUCAÇÃO A DISTÂNCIA: A mediação para aprendizagem cooperativa
}

\author{
Querte Teresinha Conzi Mehlecke ${ }^{1}$ \\ Liane Margarida Rockenbach Tarouco ${ }^{2}$
}

\begin{abstract}
Resumo: Este artigo apresenta um estudo sobre os ambientes de Educação a Distância que propiciem a interatividade, cooperação e aprendizagem entre os envolvidos. Também pretende apresentar subsídios para a reflexão das ferramentas de comunicação utilizadas em ambientes virtuais de aprendizagem.

Palavras-chave: educação a distância, ferramentas para educação a distância, comunicação síncrona e assíncrona.

Abstract: This article aims at presenting a study on Distance Learning environments that promote interactivity, cooperation and learning among participants. It also intends to offer subsidy for reflection upon the communication tools utilized in virtual learning environments.
\end{abstract}

Key words: distance learning, distance learning tools, synchronous and asynchronous communication.

\section{Introdução}

O desenvolvimento de novas tecnologias de informação e comunicação tem sido, no decorrer dos anos, um agente relevante de aprendizagem que conduz à expansão das oportunidades de combinação de recursos tecnológicos e humanos. A Educação a Distância, portanto, decorre da necessidade de novas propostas de estudo, onde o aluno não tem uma delimitação geográfica e nem uma sala de aula presencial para buscar sua qualificação. Por isso, estudos sobre a utilização das ferramentas disponíveis nos ambientes de educação a distância, faz-se necessário para que os recursos empregados não sejam um restritor para a aprendizagem no meio virtual.

A utilização dos ambientes de aprendizagem virtual, em decorrência, é o ponto principal da comunicação entre alunos e professores dispersos geograficamente. Ao escolher um determinado ambiente para $\mathrm{EaD}$, os profissionais envolvidos devem ter conhecimento suficiente sobre as implicações de tal escolha assim como objetivos claros a serem alcançados, preservando a credibilidade e a seriedade dos cursos oferecidos.

\footnotetext{
${ }^{1}$ Doutoranda do Programa de Pós-Graduação em Informática na Educação- UFRGS/PGIE

2 Professora $\mathrm{Dr}^{\mathrm{a}}$ do Programa de Pós-Graduação em Ciência da Computação/ UFRGS e do Programa de PósGraduação em Informática na Educação da UFRGS. Diretora do Centro Interdisciplinar de Novas Tecnologias na Educação/CINTED
} 
Definimos "ambientes de aprendizagem" como sistemas de ensino e aprendizagem integrados e abrangentes capazes de promover o engajamento do aluno (Black\& McClintock, 1996; Dewey, 1933 in Coscarelli, 2002).

Neste processo, "Os estudantes não devem ser objetos, mas, sim, sujeitos do processo de aprendizagem. Por isso devem ser criadas situações de ensino e aprendizagem nas quais eles mesmos possam organizar seu estudo(princípio do estudo autônomo). $O$ próprio estudo não é iniciado e dirigido por eventos expositivos $e$ receptivos ritualizados, mas, sim, por meio de discussão e interação (princípio do estudo por meio de comunicação e interação)." (Peters, 2001, p. 179)

A interação num ambiente virtual de aprendizagem é fundamental para que os alunos possam organizar suas idéias, compartilhar seus conhecimentos tornado-se sujeitos autônomos de sua aprendizagem.

Disponibilizar um ambiente de aprendizagem virtual que propicie a cooperação e a interatividade requer, fundamentalmente, algumas ferramentas que suportem tais interações. A fim de prover essas funcionalidades, apresenta-se, a seguir, algumas ferramentas que podem promover tais requisitos.

Na seção 2, são descritos, em primeiro lugar, os componentes do sistema de Educação a Distância referenciados por Landim(1997), seguidos dos modelos para o ensino a distância de Peters(2002).

A seção 3 apresenta as ferramentas utilizadas nos ambientes virtuais de aprendizagem.

A seção 4 apresenta as teorias de aprendizagem a serem consideradas nos ambientes virtuais de aprendizagem.

A seção 5 apresenta ambientes de suporte para Educação à Distância

E, finalmente, na seção 6, apresenta-se as considerações finais sobre as ferramentas e ambientes de suporte para educação a distância

\section{Componentes do sistema de Educação a Distância}

O uso das ferramentas tecnológicas, que promovem a comunicação, auxiliam professores e alunos no processo de ensino e aprendizagem a distância, criando novas possibilidades de ensino não presencial através da rede Internet.

Landim(1997), apresenta quatro características necessárias para o sistema de educação a distância:

- O aluno como sendo o centro do processo educativo.

- O docente que será o motivador e possibilitador da aprendizagem cooperativa e interativa no ambiente virtual.

- A comunicação que poderá ser realizada através de material impresso, audiovisual, telemática (Internet, softwares, CD-ROM, vídeo interativo, hipermídia, entre outros) e a tutoria mediando o presencial e o virtual.

- A estrutura e organização dos materiais, da distribuição de materiais, processos de comunicação e avaliação, fazem parte do processo inicial no desenvolvimento de programas de ensino a distância. 
Às características apresentadas por Landim, acrescentaria mais uma, que corresponderia ao "tutor", citado por ela dentro da ação do docente: “...tutor, assessor, conselheiro, animadores, que motivam a aprendizagem e resolvem as dúvidas e os problemas surgidos no estudo dos alunos $e$, neste caso, avaliam as aprendizagens"(p.39). Por mais que o professor exerça esta função, faz-se necessária a ação do tutor que aqui passaria a se chamar de "monitor", levando em consideração algumas participações e auxílio ao professor quanto ao atendimento dos alunos em diferentes horários.

$\mathrm{Na}$ seqüência, apresenta-se os diferentes modelos de ensino a distância, relacionados por Peters(2001):

* Ensino por correspondência: material impresso (livros didáticos).

* Ensino a distância clássico: material diversificado como material impresso, televisão, rádio, audiovisuais, tutores.

* Ensino a distância com base na pesquisa: caracterizado pela leitura de cursos de ensino a distância impressos e na freqüência parcialmente obrigatória em seminários. Concede apenas o grau superior ou de mestre.

* Ensino a distância grupal: programações didáticas por rádio e televisão associadas a atividades regulares obrigatórias, com presença.

* Ensino a distância autônomo: planejar, organizar e implementar isoladamente. A universidade apenas aconselha, incentiva, assiste e fornece certificado.

* Ensino a distância por teleconferência: oferecido por um consórcio de universidades para estudantes das universidades-membro e também a outras instituições.

* Ensino a distância com base em quatro formas de teleconferência: podem participar estudantes avulsos e grupos de estudantes em seus locais de trabalho, ligados por sua vez à atividade docente das universidades que cooperam com o projeto.

Os modelos acima apresentados, são flexíveis e variáveis, o que torna o ensino a distância adaptável às diferentes situações e necessidades.

\section{Ferramentas utilizadas em ambientes virtuais de aprendizagem}

Os ambientes de educação a distância apresentam uma diversidade de ferramentas que podem promover tanto a comunicação síncrona como assíncrona. Apresenta-se, a seguir, o que compõe cada comunicação:

Comunicação assíncrona:

$\Rightarrow$ E-mail: forma digital de correspondência enviada pela rede Internet;

$\Rightarrow$ Grupos de discussão: Estimulam a troca de informações através de mensagens entre vários membros de uma comunidade virtual que têm interesses afins. Chamada também de lista de discussão;

$\Rightarrow$ World Wide Web (WWW): definida como um grande sistema de informações que permite a recuperação de informação hipermídia. Ela possibilita o acesso universal de um grande número de pessoas a um grande universo de documentos;

$\Rightarrow$ FTP e Download: disponibilização de arquivos contendo áudio, texto, imagens ou vídeos; 
$\Rightarrow$ Vídeo e Áudio sob demanda: permite assistir-se, assíncronamente, vídeos ou áudios previamente gravados e armazenados no servidor.

Comunicação síncrona:

$\Rightarrow$ Chat: Comunicação em tempo real entre duas ou mais pessoas, conhecida também como bate-papo;

$\Rightarrow$ Videoconferência: Comunicação bidirecional através de envio de áudio e vídeo em tempo real, via Web, por meio de câmeras acopladas ao computador;

$\Rightarrow$ Teleconferência: Definida como todo o tipo de conferência a distância em tempo real, envolvendo transmissão e recepção de diversos tipos de mídia, assim como suas combinações;

$\Rightarrow$ Áudio-conferência: Sistema de transmissão de áudio, recebido por um ou mais usuários simultaneamente.

A utilização de outros recursos tais como CDRoms, fitas de vídeo, disquetes e materiais impressos, é uma forma de complementar e auxiliar os alunos com maior dificuldade de acesso à Internet. Dessa forma, a inclusão de outros recursos para os cursos virtuais facilitará, em alguns casos, o acompanhamento dos alunos que têm dificuldades em suas conexões com a Internet nos cursos virtuais.

O importante é levar o conhecimento aos mais diversos pontos, independentemente das tecnologias utilizadas. Isso não quer dizer que a qualidade dos materiais tenha que ser inferior às disponíveis na rede. Ao contrário, pois os materiais devem ser bem elaborados dadas as dificuldades de comunicação entre alunos, monitores e professores. Peters(2002) fundamenta a presente argumentação, dizendo:

"Caso de desenvolverem ainda mais o hardware e o software necessários para isso, será possível fazer uma combinação das técnicas de ensino e aprendizagem discutidas até agora e, em parte, também integrá-las. Então os estudantes poderão desenvolver em seu ambiente digital de estudo tantas atividades de estudo jamais possiveis antes e em qualquer lugar. Eles então não utilizarão somente cursos de ensino à distância alternativos multimediais através do CD-ROM, Internet ou ISDN, não apenas dialogarão com outros estudantes e não apenas participarão de preleções, seminários, exercícios e aulas práticas virtuais na forma de teleconferência, mas também tirarão proveito de outras funções, como as oferece uma universidade no campus real. Desse modo descortinam-se os primeiros contornos de uma universidade virtual. ( p. 270-271)

\section{A influência das teorias de aprendizagem nos ambientes de educação a distância}

Segundo Moran(2002), aprendemos melhor quando vivenciamos, experimentamos, sentimos, quando relacionamos, estabelecemos vínculos, laços, entre o que estava solto, caótico, disperso, integrando-se em um novo contexto, dando-lhe significado, encontrando um novo sentido. Aprendemos pelo pensamento, pelo encontro com o significado, quando interagimos com o mundo, pelo interesse, pela necessidade, pelo desejo de conhecer, de interagir com o meio social e cultural diverso. "Aprendemos realmente quando conseguimos transformar nossa vida em um processo 
permanente, paciente, confiante e afetuoso de aprendizagem. ...paciente porque nunca acaba. Paciente porque os resultados sem sempre aparecem imediatamente e sempre se modificam. Confiante, porque aprendemos mais se temos uma atitude confiante, positiva, diante da vida, do mundo e de nós mesmos. Processo afetuoso, impregnado de carinho, ternura, de compreensão, porque nos faz avançar muito mais.(p.24)

Apesar de aprender por diversos meios, Landim(1997) apresenta formas de aprendizagem em que em determinados fatores propiciam uma maior aprendizagem e retenção do conhecimento.

Vejamos os dados a seguir:

\begin{tabular}{|l|l|}
\hline \multicolumn{2}{|c|}{ Conhecimento } \\
\hline Como se aprende & Como se retém \\
\hline $1,0 \%$ em função do gosto & $10 \%$ do que se lê \\
\hline $1,5 \%$ em função do tato & $20 \%$ do que se escuta \\
\hline $3,5 \%$ em função do olfato & $30 \%$ do que se v \\
\hline $11,0 \%$ em função da audição & $50 \%$ do que se vê e escuta \\
\hline $83,0 \%$ em função da visão & $70 \%$ do que se diz e se discute \\
\hline & $90 \%$ do que se diz e logo se faz \\
\hline
\end{tabular}

(Landim1997, p.99)

No contexto acima referenciado, pode-se inferir que, se aprendemos mais em função do que vemos e menos por meio dos outros sentidos, retemos conseqüentemente maior conhecimento quando dizemos algo, surgindo em decorrência a ação. Neste caso, poderia-se afirmar que os ambientes virtuais de aprendizagem são ferramentas potenciais para a aprendizagem, pois ao navegar no ambiente o aluno não só estará visualizando, participando, interagindo, cooperando, como construindo o conhecimento.

Piaget(1998), ao conceituar a noção de cooperação, afirma: "A cooperação, com efeito, é um método característico da sociedade que se constrói pela reciprocidade dos trabalhadores e a implica, ou seja, é precisamente uma norma racional e moral indispensável para a formação das personalidades, ao passo que a coerção fundada apenas sobre a autoridade dos mais velhos ou do costume, nada mais é que a cristalização da sociedade já construída e enquanto tal personalidade não tem justamente nada de oposto às realidades sociais, pois constitui, ao contrário, o produto por excelência da cooperação." ( p. 141)

Os recursos da Internet utilizados como suporte à comunicação, tais como as salas de bate-papo, mural eletrônico, quadro compartilhado, fórum, áudio e videoconferência são exemplos de mecanismos disponíveis que permitem ampliar a interação e comunicação em atividades de EAD e que ganham relevância na medida em que uma nova maneira de produzir conhecimento vem se instalando com o computador, veiculando a possibilidade de se aprender, fazendo.

Nesta linha, Santoro(2002), destaca as teorias de aprendizagem em ambientes virtuais como sendo 'um dos fatores mais importantes que regulam a colaboraç ão é a 
teoria da aprendizagem a qual a interação cooperativa será baseada, buscando reconhecer a dinâmica envolvida nos atos de ensinar e aprender partindo do reconhecimento da evolução cognitiva do homem..."

De acordo com os estudos de framework de Santoro, salientam-se algumas características interessantes de serem observadas nos ambientes de aprendizagem virtual desenvolvidos pela pesquisadora, a saber:

\section{-Comunicação}

-Síncrona e assíncrona

-Grau de Interação

-Pequeno, Médio ou Grande

- Coordenação

- Objeto gerenciado - direitos para gerenciar uma ação

-Negociação e tomada de decisão

-Livre ou estruturado

-Representação de conhecimentos

-Discussões - coletivas e individuais

-Memória de grupo

-Ficam registrados e armazenados todas as i

-Percepção

-Online e off line

-Designação de Papéis

-Direitos distintos

-Responsabilidades diferenciadas

interações dos fóruns e mensagens

De acordo com Cosacarelli(2002) a integração de conhecimentos e saberes de diversas áreas é a marca de ambientes de parendizagem. Na integração multidisciplinar (conteúdo cruzado), as fronteiras implícitas ou explícitas entre as disciplinas são minimizadas pela utilização, integração e exploração de informação, conceitos e habilidades, numa variedade de contextos diferentes. No caso da integração intradisciplinar, as relações acontecem dentro dos limites de uma única disciplina.

\section{Ambientes de suporte para educação a distância}

Segundo Alava (2002), o ensino presencial continua sendo o mais utilizado nas Universidades, onde o professor é o único responsável pelo conteúdo. Já no ensino meditizado, ele não é mais a fonte principal de informação, o dono do saber, ele se torna um facilitador da aprendizagem, tornando o ensino mais interativo, obrigando o professor conhecer novas tecnologias, variando as abordagens pedagógicas para facilitar o aprendizado dos estudantes.

Dentro desse contexto, nesta seção apresenta-se alguns ambientes de suporte para educação a distância que são utilizados para mediação entre professores e alunos nos encontros virtuais. 


\section{Learning Space}

O Learning Space, é um ambiente para Educação à Distância desenvolvido pela Lótus utilizando por algumas Instituições de Ensino Superior. [www.lotus.com ]

Cinco módulos de treinamento colaborativo combinam-se para oferecer um ambiente integrado que suporta o aprendizado baseado em equipes e facilitado pelo instrutor. Os módulos são:

a) Schedule - Oferece recursos como as páginas de abertura.

b) MediaCenter - Recursos para o desenvolvimento de cursos para instrutores como habilidade de incorporar facilmente multimídia(incluindo vídeos e animações).

c) CourseRoom - É o ambiente interativo para colaboração entre aluno/equipe, aluno/aluno e aluno/instrutor.

d) Profiles - É um repositório de "home pages" criadas pelos alunos. Seus novos recursos incluem habilidade de manter confidenciais as informações de telefone e endereço, opção de usar apelidos para identificação online,

e) Assessment Manager - Ferramenta totalmente reestruturada, para que os instrutores possam avaliar os alunos e dar-lhe um retorno de seu aproveitamento.

f) Customize - Ferramenta para alterar a aparência do Learning Space e construir funções e módulos personalizados.

g) Central - ferramenta para gerenciar a criação, instalação, configuração e processos de matrícula/acesso de alunos aos cursos Learning Space. Inclui nesse recurso o CoursePacks que facilita o gerenciamento e a distribuição do conteúdo para cursos existentes e ferramentas para copiar e transferir cursos existentes.

Página inicial do Learning Space. Os usuários devem ser cadastrados pelo administrador, para assim ter acesso ao ambiente.

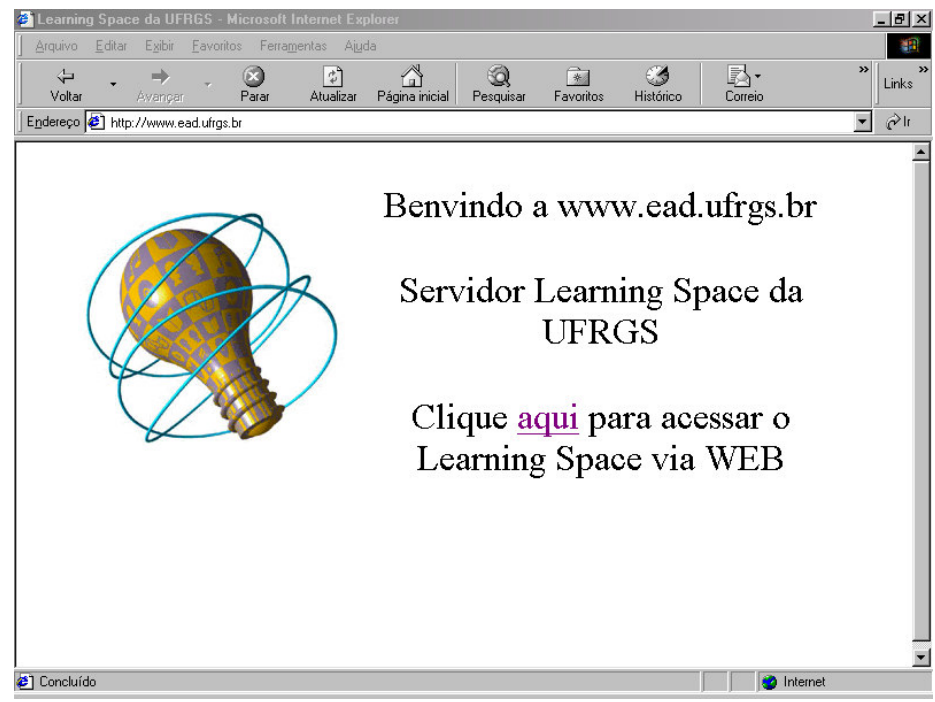


Fig. 1 www.ead.ufrgs.br

\section{Aula Net}

AulaNet é um ambiente de software gratuito desenvolvido no $\mathrm{LES}^{3} / \mathrm{PUC} / \mathrm{RJ}$, para o ensino e aprendizagem baseados na Web para criação e manutenção de cursos à distância. [http://anauel.cead.puc-rio.br/aulanet2/]

"AulaNet: é baseada numa abordagem cooperativa - comunicação, coordenação e cooperação - enquanto a maioria dos outros ambientes relacionados virtualizam os elementos físicos da escola tradicional: corredores, quadros-negros, secretarias, sala de aula, bibliotecas, etc..." [http://anauel.cead.puc-rio.br/aulanet2/]

Página inicial do AulaNet. Os usuários devem ser cadastrados pelo administrador, para assim ter acesso ao ambiente.

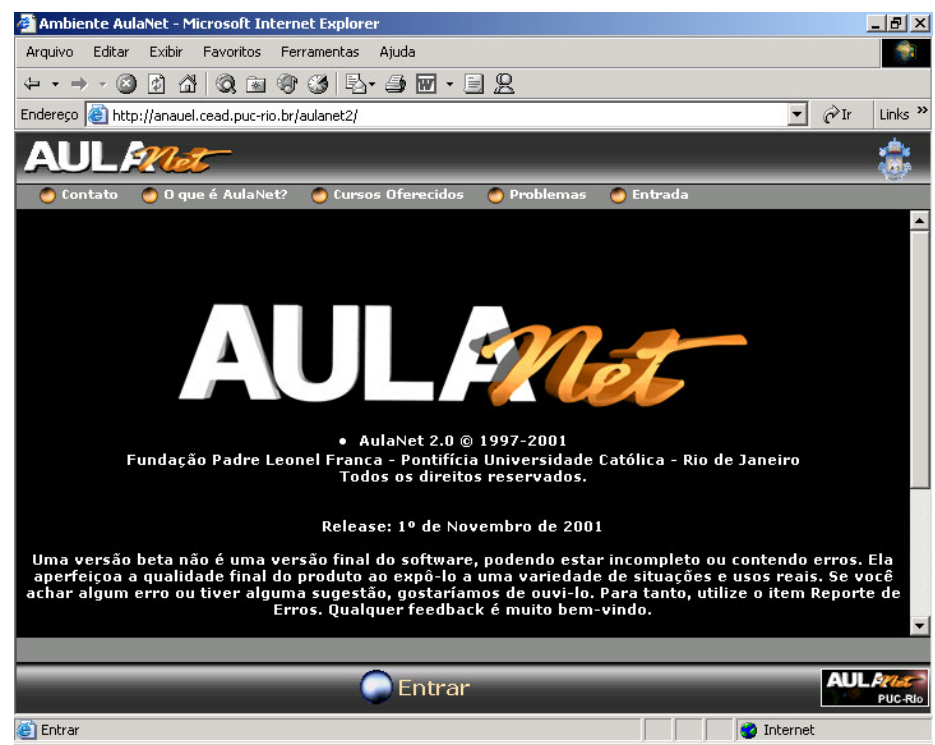

Fig. 2 http://anauel.cead.puc-rio.br/aulanet2/

"A explosão do número de ambientes de educação à distância pode ser creditada em parte, à Internet, sede virtual da cultura de comunicação digital em constante expansão. Existem três aplicações Internet essenciais ao AulaNet: o correio eletrônico, a WWW e a vídeoconferência digital." (Lucena, p. 107 Anais SBC)

O Aula Net se fundamenta nas seguintes premissas:

\footnotetext{
${ }^{3}$ Laboratório de Engenharia de Software.
} 
- O autor do curso não precisa ser um especialista em Internet,

- O autor do curso deve enfatizar a interatividade de forma a atrair a participação intensa do aprendiz,

- Deve ser possível a reutilização de conteúdos já existentes em mídia digital, através, por exemplo, da importação de arquivos.

\section{TelEduc}

O TelEduc é um ambiente para criação, participação e administração de cursos na Web. Ele foi concebido tendo como alvo o processo de formação dos professores para informática educativa, baseado na metodologia de formação contextualizada desenvolvida por pesquisadores no $\mathrm{NIED}^{4}$ da Unicamp. O TelEduc foi desenvolvido de forma participativa, ou seja, todas as suas ferramentas foram idealizadas, projeto das e depuradas segundo necessidades relatadas por seus usuários. Com isso, ele apresenta características que o diferenciam dos demais ambientes para educação à Distância disponíveis no mercado, com a facilidade de uso por pessoas não especialistas em computação, a flexibilidade quanto a como usá-lo, e um conjunto enxuto de funcionalidades. A característica principal do Ambiente TelEduc é a disponibilização de atividades.

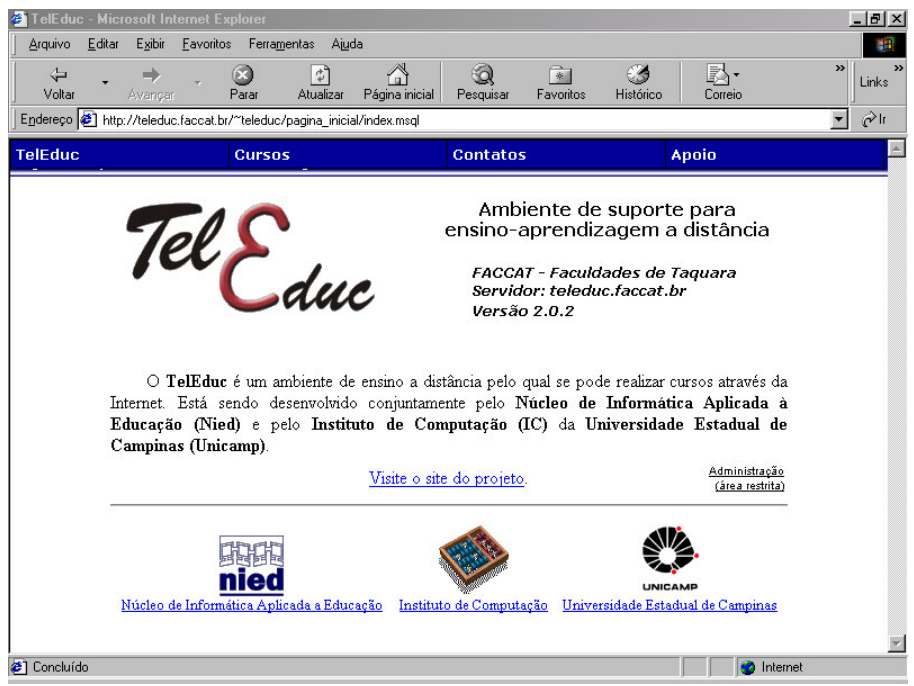

Fig 3 http://teleduc.faccat.br/ teleduc

\section{Gestum}

A Gestum foi criada em 1999, com a missão de desenvolver soluções para elearning, composta de várias metodologias e ferramentas para o desenvolvimento de treinamento via Web.

\footnotetext{
${ }^{4}$ Núcleo de Informática Aplicada à Educação.
} 


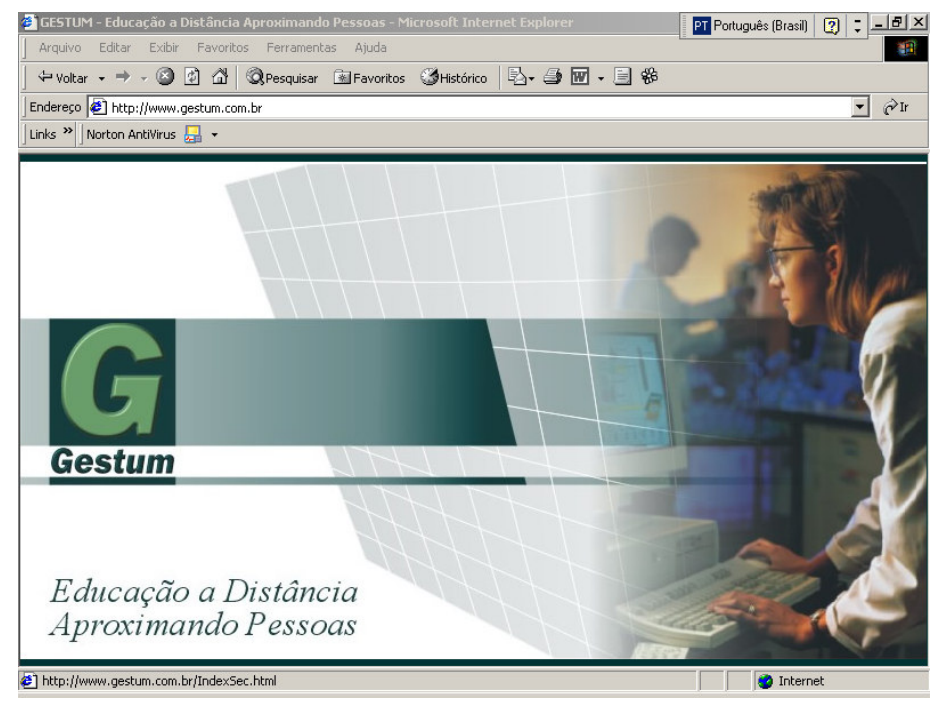

Fig 4 http://gestum.com.br

\section{Ambiente de Criação de Conteúdo ACC}

Ambiente extremamente amigável, requer conhecimentos básicos de informática para sua utilização. É uma ferramenta wysiwyg, o que permite ao conteudista visualizar a produção do conteúdo no mesmo formato de sua publicação.

O ambiente ACC é de fácil utilização, pois é muito semelhante a um editor de textos, com isso o professor não precisa ser um especialista em informática para disponibilizar seu conteúdo na Web.

Este ambiente comporta áudio, vídeo, imagens, gif's animados, flasch entre outros recursos, sendo que o professor em apenas um clic do mouse insere as imagens, os vídeos, gráficos, etc. O ACC tem um padrão de tamanho que, mesmo que a figura seja grande, ele organiza dentro do espaço destinado a ele sem alterar na qualidade dos mesmos. 


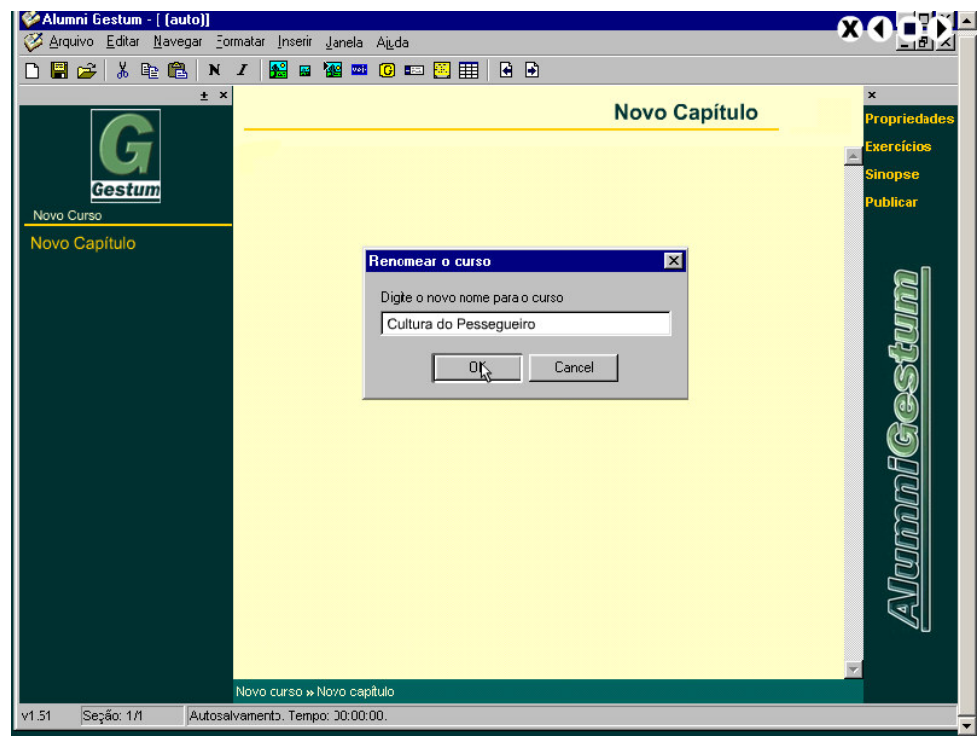

Fig 5 Ambiente ACC - http://www.gestum.com.br

\section{Considerações finais}

De acordo com Moran (2000) 'Estamos numa fase de transição na educação à distância. Muitas organizações estão limitando-se a transpor para o virtual adaptações do ensino presencial (aula multiplicada ou disponibilizada). Há um predomínio de interação virtual fria(formulários, rotinas, provas, e-mail) e alguma interação on-line. Começamos a passar dos modelos predominante individuais para os grupais. A educação à distância mudará radicalmente de concepção de individualista para mais grupal, de utilização predominante isolada para utilização participativa, em grupos. Das mídias unidirecionais, como jornal, a televisão e o rádio, caminhamos para mídias mais interativas. Da comunicação off line evoluímos para um mix de comunicação off $e$ on line (em tempo real)."( $p .143)$

É importante salientar que os ambientes de suporte para educação a distância, por mais que ofereçam ferramentas que propiciem a cooperação e interação, não irão conseguir sozinhos que os alunos construam seus conhecimentos se não tiverem uma equipe interdisciplinar que se acompanhe, tanto alunos quanto professores. Pois o acompanhamento é o ponto fundamental para o funcionamento dos ambientes e a construção da aprendizagem.

Ter ambientes ricos em ferramentas interativas é importantes, mas, o mais importante é os profissionais estarem preparados para utilizar estes recursos a fim de promover as interações, cooperações de todos os envolvidos no processo de ensino e aprendizagem virtual.

Contudo, precisa-se estar ciente da responsabilidade e da credibilidade ou disponibilizar cursos à distância, seja via web ou outro meio convencional como materiais impressos. $\mathrm{O}$ ambiente escolhido, o suporte técnico e os monitores não atendem todas as necessidades para um curso de qualidade a distância. Deve haver um planejamento sério e professores comprometidos com os alunos dos programas à 
distância. Todos devem ter bem claros os objetivos didáticos a serem alcançados, buscando a credibilidade e a seriedade dos cursos oferecidos.

\section{Referências bibliográficas}

ALAVA, Séraphin \& Colaboradores. Ciperespaço e Formações Abertas. Rumo a Novas Práticas Educacionais? Porto Alegre/RS : Artes Médicas. 2002.

BELlONI, Maria Luiza. Educação a Distância. São Paulo : Autores Associados. $2^{\mathrm{a}}$ ed. 1999.

CARRETERO, Mario. Construtivismo e Educação. Porto Alegre, Artes Médicas, 1997

COSCARELLI, Carla Viana(Organizadora). Novas tecnologias, novos textos, novas formas de pensar. Belo Horizonte : Autêntica, 2002.

FISCHER, Graciana Simone; LIMA, José Valdeni; Tarouco, Liane M. Rockenbach. Um Ambiente Virtual Multimídia de Ensino na Web, com Transmissão ao Vivo e Interatividade. I Congresso Brasileiro de Computação - CBComp 2001. Acesso em: http://www.cbcomp.univali.br/pdf/INE007.PDF - 10 de março de 2002. http://www.sead.ufrj.br/esud/material/LianeTarouco.doc

JAQUES, Patrícia Augustin. Agentes de Software no Ensino Colaborativo a Distância. Artigo no site: <http://www.inf.ufrgs.br/ pjaques/papers/ti2/cap4.htm> consultado em 17 de fevereiro de 2003.

LUCENA, J.P. Carlos; FUKS, Hugo; MILIDIU, Ruy; LAUFER, Carlos; BLOIS, Marcelo; CHOREN, Ricardo; TORRES, Viviane; FERRAZ, Fabio; ROBISCHEZ, Gustavo; DALFLON, Leandro. AulaNet: Ajudando professores a fazerem seu dever de casa. Anais SBC'1999, Rio de Janeiro, de 19 a 23 de julho de 1999.

MAIA, Carmem. Guia brasileiro de educação à distância 2000/2001. São Paulo : Esfera, 2001.

MEADOWS, A . J. A Comunicação Científica. Brasília, Briquet de Lemos/Livros, 1999. 268p.

MONTANGERO, Jacques; MAURICE-NAVILLE, Danielle. Piaget ou a Inteligência em Evolução. Porto Alegre, Artes Médicas. 1998. 242p.

MORAN, José Manuel. Ensino e Aprendizagem Inovadores com Tecnologia. Informática na Educação: Teoria \& Prática/ Programa de Pós-Graduação em Informática na Educação. - vol 3, (set 2000) -.- Porto Alegre : UFRGS. Programa de Pós-Graduação em Informática na Educação, 2000-v. pg 137/144. 
Otsuka, Joice Lee. Fatores determinantes na efetividade de ferramentas de comunicãção mediada por computador no ensino a distância. http://penta.ufrgs.br/pesquisa/joice/joice tl.html

PAZ, Helena Rodrigues. Aprendizagem de Adultos em Ambientes virtuais on-line. http://www.idilica.com.br/pdfs/F EJA2001.PDF. Consultado em 02 de fevereiro de 2003.

PETERS, Otto. Didática do Ensino a Distância. São Leopoldo,RS : UNISINOS, 2001.

PIAGET, Jean. O Nascimento da Inteligência na Criança. Rio de Janeiro, Zahar, 1979.

Problemas de Psicologia Genética. São Paulo, Florense,1973.

Sobre Pedagogia. São Paulo, Casa do Psicólogo, 1998.

SANTORO, Flávia M.; Borges ,Marcos R.S.; Santos Neide. Ambientes de Aprendizagem do Futuro: Teoria e Tecnologia para Cooperação. XIII Simpósio Brasileiro de Informática e Educação - SBIE 2002

SANTORO, Flávia M.; Borges, Marcos R.S.; Santos Neide. Um Framework para estudo de ambientes de suporte à aprendizagem cooperativa. Simpósio brasileiro de informática educativa. Anais do SBIE 2002.

Tarouco, Liane M.R. O Processo de Avaliação em Educação a Distância. Artigo no site:http://www.pgie.ufrgs.br/webfolioead/biblioteca/artigo6/artigo6.html consultado em outubro de 2002. 